Supporting Information

\title{
Synthesis of a Macrobicycle Incorporating the Tris(pyrazolyl)methane ligand
}

\author{
Leyong Wang and Jean-Claude Chambron*
}

Université de Bourgogne, Laboratoire d'Ingénierie Moléculaire pour la Séparation et les Applications des Gaz (CNRS, UMR 5633), 6, boulevard Gabriel, 21100 Dijon, France.

\section{Jean-Claude.Chambron@u-bourgogne.fr}

Figure S1: ${ }^{1} \mathrm{H}-\mathrm{NMR}$ spectrum (500 MHz, $\mathrm{d}^{6}$-acetone) of macrobicycle 2. Residual solvent peaks are marked with an asterisk.

Figure S2 : ${ }^{1} \mathrm{H}-\mathrm{NMR}$ spectrum (500 MHz, $\mathrm{d}^{6}$-acetone) of macrobicycle 2. Detail of the region of aromatic protons.

Figure S3 : ${ }^{13} \mathrm{C}-\mathrm{NMR}$ spectrum $\left(75 \mathrm{MHz}, \mathrm{CDCl}_{3}\right)$ of macrobicycle 2. Residual solvent peaks are marked with an asterisk.

Figure S4 : FT-IR spectrum (KBr pellet) of macrobicycle 2.

Figure S5 : MALDI-TOF spectrum (dithranol matrix) of macrobicycle 2. Peaks arising from the matrix are marked with an asterisk. 